\title{
Crétois, Pierre. La part commune. Critique de la propriété privée. Paris: Éditions Amsterdam, 2020.
}

\author{
Clara Esteve Jordà \\ Departamento de Derecho Público \\ Universitat Rovira i Virgili
}

Fecha de recepción 26/10/2021 I De publicación: 23/12/2021

Ciertamente, las críticas a la propiedad forman parte del debate público actual. La monopolización privativa de bienes y servicios provocada por el liberalismo económico ha aumentado la desigualdad y ha contribuido a la crisis medioambiental. He aquí la paradoja: Si la apropiación privativa está tan a menudo en conflicto con los imperativos de la justicia, ¿por qué no abolirla simplemente afirmando una comunidad "sana" de bienes? La obra de Pierre Crétois, filósofo y profesor en la Université BordeauxMontaigne, aborda esta cuestión y propone trazar unas bases para deconstruir el absolutismo propietario y repensar la propiedad en pro de lo común.

Con un estilo estimulante, Crétois se encarga minuciosamente de desmitificar la idealización de una propiedad absolutamente privada. Afirma que, de hecho, nunca ha existido la propiedad privada como tal. Las cosas no pueden ser objeto de apropiación, sino instrumentos de desarrollo de actividades individuales y colectivas. Así, el autor propone un concepto de propiedad en el que el individuo propietario ya no es concebido como un déspota sobre su dominio, sino como un miembro de comunidades y ecosistemas. Afirma, pues, que no hay camino de transición hacia la emancipación sin la transformación de la propiedad.

Para ello, Pierre Crétois aborda el concepto desde sus raíces. Sitúa el surgimiento de la propiedad privada moderno en el Renacimiento y analiza su definición como derecho natural del individuo a disfrutar de los frutos de su trabajo como le parezca. La Revolución Francesa consagró esta idea en la Declaración de los Derechos del Hombre y el Ciudadano, considerándola una condición sine qua non de la libertad y la democracia. Ello sirvió para consolidar la propiedad privada como elemento central en el constitucionalismo liberal hegemónico, y crucial para el despliegue de otros derechos fundamentales. 
El ensayo de Pierre Crétois abre con una introducción (pp. 11-26), dividiéndose a continuación en cuatro capítulos. En el primero de ellos, 1. Propriété privée. Anatomie d’un concept (pp. 27-68), realiza un escaneo del concepto de propiedad y lo desgrana, apoyándose en argumentos históricos y en las teorías de los grandes pensadores de la ilustración, las cuales serían decisivas para todo el pensamiento jurídico moderno. Sobre la base del capítulo V del Segundo Tratado sobre el Gobierno Civil (1690), del filósofo inglés John Locke, Crétois proporciona una definición moderna de la ideología propietaria, cosiendo todos los elementos que componen su concepto: a) es un derecho natural arraigado en el individuo; b) que se adquiere mediante el trabajo individual; c) cuyo valor producido constituye un mérito individual incontestable; d) que presupone una libertad absoluta (disfrutar, usar, explotar, vender, destruir...), por lo que no permite ninguna limitación o interferencia por parte de los demás. Crétois manifiesta abiertamente su oposición a esta presunción de la noción de propiedad, pues implicaría sostener como natural lo que considera en realidad una construcción social.

Pierre Crétois sostiene entonces que el fundamento de la obligación de cada uno de respetar lo que pertenece a los demás debe ser también sobre todo político, es decir, discutido y aceptado colectivamente. Cita entonces la concepción contractualista de Rousseau, para quien sólo un pacto social puede ser la fuente de los derechos de propiedad, que quedan así subordinados al bien común. Este es el punto central de la obra: el contrato social no puede ser abusivamente desventajoso para ninguna de las partes ni irreconciliable con el bien común. Al sugerir que siempre hay algo irreductiblemente común en lo propio, los derechos de propiedad ya no pueden entenderse simplemente como derechos de separación, sino como normas de organización que vinculan a los miembros de una comunidad humana.

En el capítulo 2. Débusquer l’idéologie (pp. 69-116), el autor subraya los abusos de los derechos, piensa en la renta básica como un dividendo sobre el patrimonio común, y contrapone la discapacidad, la educación o la genética al mero mérito personal, citando a pensadores como John Rawls, Robert Nozik o Friedrich Hayek. En contraposición al mito de la meritocracia y el sistema de libre mercado, el autor propone que las cosas sean adquiridas de acuerdo con un sistema de cooperación voluntario, organizado de forma tan equitativa que no sólo no perjudique a nadie, sino que además beneficie a los más desfavorecidos. En otras palabras, la propiedad consistiría en un derecho a acceder a la parte de los recursos que le corresponde a cada individuo en base a principios equitativos de justicia.

En el tercer capítulo, 3. Repenser les règles de propriété (pp. 117 -168), Crétois realiza una propuesta analítica alternativa de la propiedad, que sería la siguiente: a) el propietario individual no es un déspota 
absoluto de su dominio, sino un miembro de comunidades y ecosistemas en los que está incluido; b) los derechos de propiedad no son absolutos ni exclusivos, sino parciales y relativos; c) no son derechos de separación, sino que precisamente nos ponen en relación con los demás. En este gesto desmitificador, Pierre Crétois muestra que siempre existe una parte común en lo que es específico de cada individuo. Esto obliga a repensar los derechos de propiedad como realidades jurídicas compuestas (y no absolutas) que pretenden regular las relaciones sociales sobre las cosas.

Finalmente, en el cuarto y último capítulo, 4. L’inappropriabilité des choses (pp. 169-208), el autor analiza nuestra relación con las cosas, para saber si son susceptibles de ser objeto de una apropiación privativa. El autor desmiente, a modo de conclusión, esta posibilidad de apropiarse de las cosas. De hecho, considera dicha apropiación irrelevante e innecesaria, pues la propiedad privada no es imprescindible para los logros del ser humano. Por un lado, la propiedad no es en el fondo un derecho del individuo de separarse de los demás y de la naturaleza, sino más bien una forma de relacionarse con el resto. Por el otro, la propiedad del individuo genera externalidades para los demás y para el medio ambiente, por lo que las cosas forman parte de un ecosistema colectivo. Precisamente por ello deben regularse las relaciones entre la propiedad y el ecosistema mediante derechos.

Apoyándose en las teorías de las capacidades de Amartya Sen y Martha Nussbaum, Crétois aboga por el acceso a las funcionalidades que las cosas pueden proporcionar mediante la puesta en común de su uso. Al fin y al cabo, lo relevante de los bienes es su posibilidad de disfrute sobre ellas, no la propiedad en sí misma. Este constituye un cuestionamiento fundamental de la idea misma de apropiación, que convertiría la propiedad, efectivamente, en "un conjunto de reglas secundarias" (p. 198). Por ello, el autor apuesta por un derecho de propiedad relativo e instrumental (nunca fundamental) para el reconocimiento de los verdaderos derechos fundamentales.

La part commune a la que se refiere Crétois implica que, en realidad, en toda propiedad existe imbricada una parte común que no pertenece al individuo, y si este quiere hacer un uso justo y equitativo de ella, debe aceptarla. Evidentemente, parece extremadamente difícil repartir, de forma objetiva, lo que corresponde al individuo propietario y lo que corresponde a los demás. Para ello, el autor propone dos recursos: 1) la democracia y 2) una teoría de la justicia distributiva, que defina la parte equitativa de cada individuo. Así pues, la parte común sería la idea según la cual la propiedad no puede ser considerada en relación exclusiva con el propietario de las cosas, sino como una forma de regular las relaciones sociales sobre cosas que son fundamentalmente inapropiables o poseídas en común. 
Es menester poner en valor la relevancia de los argumentos de Crétois en las cuestiones jurídicas relativas a la propiedad. Sus argumentos ofrecen una convincente teoría del cambio, que encaja a la perfección con los problemas en el horizonte del Derecho, en todas sus ramas jurídicas. El mundo es finito, sometido a riesgos ambientales y a crecientes desigualdades. La libertad y la justicia son, pues, incompatibles con la propiedad absoluta. Resulta esencial la reflexión de que un escenario de transición hacia los dos grandes retos del siglo XXI; la equidad y la sostenibilidad, requiere de un replanteamiento sobre el rol de esta disciplina organizativa de la actividad social. El derecho liberal a la propiedad privada, a través de la afirmación de derechos individuales y absolutos, ha fallado en proteger la existencia humana y el mundo no humano, de la manera más injusta e insostenible.

Considero muy positiva la propuesta que nos hace Pierre Crétois, quien nos confirma que el camino para avanzar hacia la justicia social y la preservación del medio ambiente pasa obligatoriamente por avanzar hacia el procomún. Resulta por ello el ensayo perfectamente trasladable (y deseable) a un eventual Derecho, como disciplina, que sostenga como base estas cuestiones. Obras como esta son, a mi entender, la base para la renovación de la teoría jurídica de la propiedad y la inspiración para la construcción de las nuevas perspectivas políticas que, de hecho, ya están tomando forma. Quien sabe. Puede que, en un futuro, la noción misma de propiedad quede obsoleta. Si las cosas son en sí mismas realidades fuera de nuestro control, las reglas de la propiedad deberán estar dirigidas a organizar las relaciones de copropiedad. Estas deberán asegurar el logro de ciertos valores y ofrecer a toda la sociedad la posibilidad de acceder a una vida plena. 